The next point treated in this paper is the available selection criteria. A distinction is made between direct estimates evaluating the abilities of the animals in practice and the indirect estimates measuring a character in correlation to the previous ones. - For the first estimates, a distinction is made between those resulting from competitions (handicap, records or earnings) and those resulting from direct in station measurements (saddle, jumping, dressage abilities, draught power).

As regards the indirect estimates, often used especially for selection of mares, the most important analysis is obviously that of the conformation. However, in the future early selection criteria according to more physiological data should be searched for and developed.

Estimation of the breeding value according to a given ability is there after pointed out. There are two situations : "The panmictic case» concerning sport and draught horses and "the non-panmictic case corresponding to racing horses, which give rise to some problems.

The setting up of breeding plans is discussed. On account of the different economic situations and various objectives of horse production, conclusions are drawn about the role played by geneticians in the present development of this sector.

\title{
Prediction of breeding values for multiple traits in small non-random mating (horse) populations
}

\author{
T. ARNASON \\ Department of Animal Breeding and Genetics, \\ Swedish University of Agricultural Sciences, 75007 Uppsala, Sweden
}

A mixed model method (Blup) is introduced for the estimation of breeding values for multiple traits of all animals included in a dataset, by utilizing the complets genetic relationship. Considerable computational simplifications are obtained by linear transformation of the variates, thus enabling the equations to be solved separately for each trait. The method is illustrated by an example. Undesirable effects of sampling variance on estimated genetic parameters are discussed and a recent method ("bending») for the improvement of defective variance matrices is recommended. Recent advances in $\mathrm{ML}$ estimation of genetic parameters are briefly reviewed.

\section{Inbreeding and infertility in the Thoroughbred mare}

\author{
G.A.T. MAHON * and E.P. CUNNINGHAM ** \\ * Department of Zoology, University College, Galway, Ireland \\ ** The Agricultural Institute, Sandymount Avenue, Dublin 4, Ireland
}

Coefficients of inbreeding were calculated for the breeding population of Thoroughbred mares in Ireland and Britain in the early 1960's. The average coefficient of inbreeding over five generations was found to be 0.01 . Coefficients of total inbreeding were estimated for a sample of 60 mares. The average coefficient of inbreeding over the 21.5 generations since the foundation of the breed was found to be 0.125 . A fertility score was calculated for each mare in the breeding population in the early 1960's. The score was based on the ratio of successful years at stud for the mare. Neither the regression of fertility score on coefficient of recent inbreeding, nor the regression of fertility score on cofficient of total inbreeding, was significant. The heritability of fertility score was estimated to be $0.077 \pm 0.030$. 